\title{
Eating (with) piranhas: \\ untamed approaches to domestication
}

\author{
Carlos Emanuel Sautchuk \\ Department of Anthropology, Universidade de Brasilia, Brasília/DF, Brazil.
}

\begin{abstract}
In this article I begin by describing my sense of ethnographic unease concerning the commensality and the conviviality of two predators in Amazonian lakes - piranhas and fishermen. From this starting point I then discuss the notion of domestication, commenting on the current tendency to reaffirm use of the term in social anthropology and revisiting two approaches: that of Jean-Pierre Digard (and other French authors) and that of Tim Ingold, both of whom make use of this notion in their ethnographic explorations of the relation between humans and animals. The article then returns to explore the potential of the notion of domestication for making explicit contemporary questions and dilemmas such as nature and culture, human and animal, subject and object. I conclude with a reflection on the ideas of domestication and predation in the relationship between piranhas and fishermen.
\end{abstract}

Keywords: Human-animals relations; fishing; predation; domestication; Amazonia.

\section{Comendo (com) piranhas:}

\section{aproximações indômitas da domesticação}

\section{Resumo}

Este artigo parte de uma inquietação etnográfica sobre a comensalidade e o convívio entre dois predadores nos lagos amazônicos - piranhas e pescadores. Deste ponto de partida será discutida a noção de domesticação, primeiro com um comentário sobre a tendência de reafirmação do termo na antropologia social e em seguida revisitando duas abordagens: a de Jean-Pierre Digard (e outros autores franceses) e a de Tim Ingold, ambos tendo feito uso desta noção como modo de tratamento dos variados sentidos e formas das relações entre humanos e animais. $O$ artigo trata então da noção de domesticação enquanto forma de explicitar questões e dilemas contemporâneos como natureza e cultura, humano e animal, sujeito e objeto. Concluo com uma reflexão sobre as ideias de predação e domesticação para compreender a relação entre piranhas e pescadores.

Palavras-chave: Relações humano-animal; pesca; predação; domesticação; Amazônia. 


\title{
Eating (with) piranhas:
}

\section{untamed approaches to domestication}

\author{
Carlos Emanuel Sautchuk
}

In this text I reflect on the use of the notion of domestication in anthropology, not as a concept used to define and frame specific practices observed in the field, but as a conceptual and empirical tool able to connect distinct approaches and temporalities, and to pose questions that destabilize certain suppositions concerning relations between humans and animals. I set out from the premise that, in anthropology at least, what matters most is not what concepts are used but how they are used. Reflecting this idea, the untamed character of my approach has two sources. The first is theoretical in kind. The very use of the notion of domestication advanced here involves a certain lack of control. In other words, my aim is not to argue for a definition or framework for the term, but rather to show how it can function as a vector for questions, dilemmas and new ethnographic approaches to the relationship between humans and animals. Other authors propose a similar use of this concept, as I shall discuss later.

The other reason for my untamed approach derives from the ethnography itself. While domestication appears as a main theme in my current research on farming of the pirarucu fish (Arapaima gigas) in Amazonia, it is the reencounter with a long-standing unease concerning the coexistence between humans and animals that animates this text. The untamed approach developed here translates the way in which the ethnography first led me to this concern with domestication through the commensality between two types of predators in the Amazonian lakes: piranhas and fishermen. What informs these reflections on domestication, therefore, is the conviviality between humans and animals in a context initially taken to be defined by the relation of predation. ${ }^{1}$

\section{Carnivorous conviviality}

Several times during the field research for my doctorate (Sautchuk 2007), for periods of a few weeks, I inhabited the stilt houses built in the coastal lakes of the state of Amapá, in the estuary region of the Amazonas River, in Brazil. During these stays, between the trips to harpoon pirarucu in the early morning and late afternoon, the fishermen would typically spend the day on the stilt house itself, relaxing and joking. These feitorias, as they are called locally, combine a minimalist architecture with a simultaneously distributed and alternating use of the small space for diverse activities. Thus the fishermen (also called caboclos and ribeirinhos in the regional idiom, or laguistas and harpooners locally)2 pass the time protecting the captured fish left to dry in the sun from attacks by birds, resting, repairing equipment, playing dominoes and above all eating.

\footnotetext{
1 Earlier versions of this text were presented on three occasions: in the conference "Other symmetries: anthropological dialogues on humans and animals," held at the Federal University of Rio Grande do Sul in 2014; at the seminar "Domestication in debate: concepts, practices and natures," held in 2015 at the Department of Anthropology of the University of Brasília, co-organised by the Institut de recherche pour le développement (IRD, France) and in a reading group run by the Artic Domus project at the University of Aberdeen in 2016. These debates were decisive in terms of the evolution of the ideas in this article, for which I thank the participants and organizers.

2 Caboclo is a Brazilian complex term for someone of mixed indigenous, African and/or European ancestry in the Amazon (for an in-depth discussion, see Harris 1998 and Adams et al. 2009), while ribeirinho literally means 'river dweller' and laguista can be translated as 'lake fishermen.'
} 


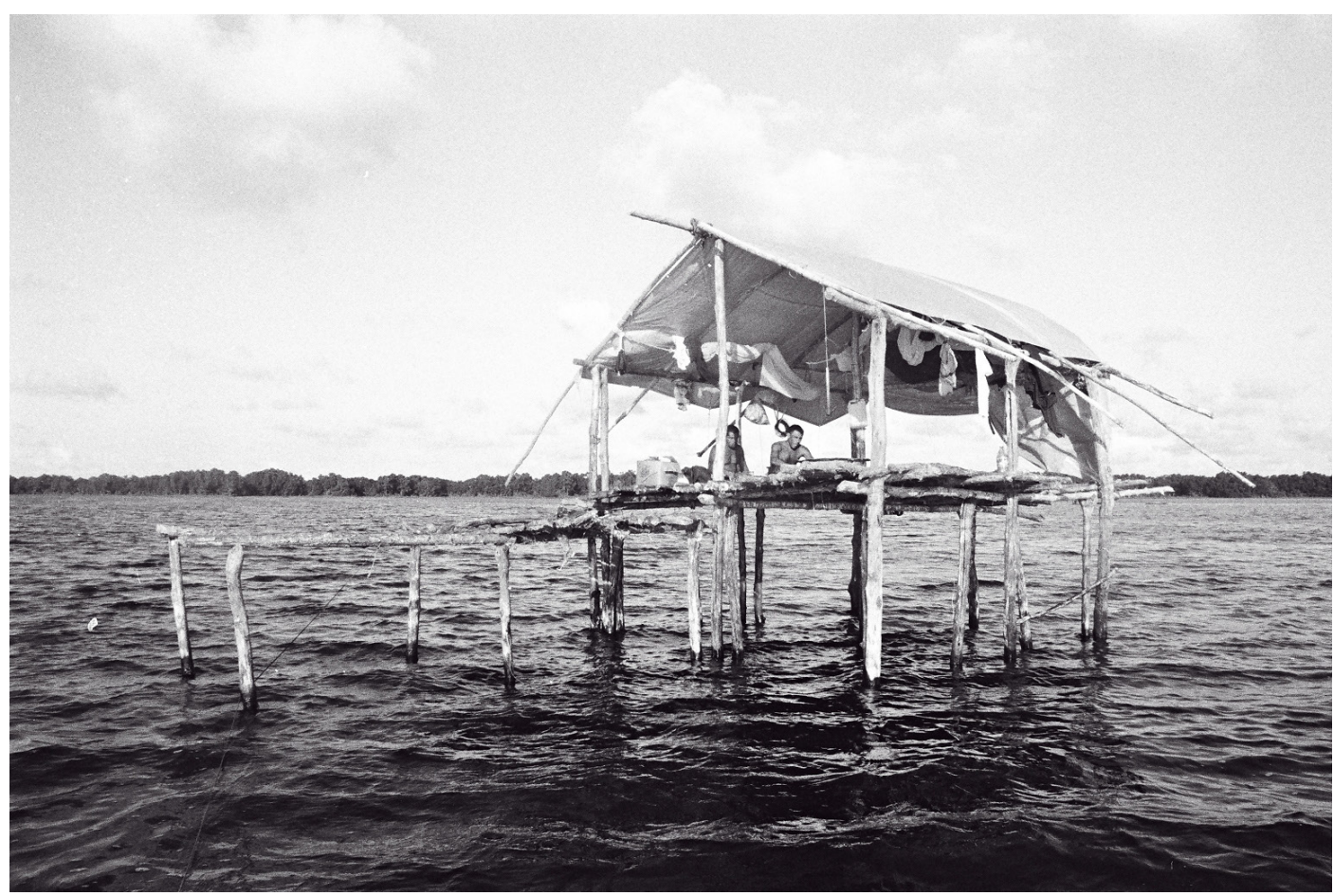

Figure 1 - Macó and Gero rest on the feitoria (stilt house) in the dry season. During the rainy season the water level almost reaches the habitation deck. (Author's photo)

The lake fishermen are inveterate gourmets, a proclivity favoured by their environment, which supplies them with innumerable options of animal and plant origin. During meals, the company of other insatiable beings - the piranhas - is fairly constant and eye-catching. Moving frenetically under the stilt house, the shoals are formed by two species of these carnivorous fish - one of them small, up to $20 \mathrm{~cm}$, the red-bellied piranha (Pygocentrus nattereri), and the other larger, up to $40 \mathrm{~cm}$, called 'pá de remo' (paddle blade) locally, or the black piranha in English (Serrasalmus rhombeus).

During the meals eaten on the stilt house deck, bits of fish slip or are dropped through the floorboards, falling into the agile jaws of the piranhas a few dozen centimetres below, often snapped mid-air. The fishermen are unfazed by this partnership, and even enjoy it, accompanying the gesture of offering the fish bits of food with remarks lauding their own generosity or the insatiable appetite of these aquatic commensals. On such occasions, they feed themselves in the company of the lake fishermen. If the fish become overly agitated and splash water upwards, though, they are instantly admonished with exclamations that they are welcome to eat but not to be so annoying.

In these lakes where everyone (human or not) who eats well, i.e. a lot, is complimented on the fact, the lake fishermen regard the fat piranhas as if they were well-fed xerimbabos (pets). Indeed sometimes they call them by this term, in a mostly non-literal but still affectionate form, identifying their predatory attributes, highly valorised in the region. A buzz of excitement occurs whenever a pirarucu carcass is thrown in the water and the piranhas immediately attack it, devouring the rest of the flesh voraciously, leaving any remains to sink to the lake bottom awaiting the nocturnal visit of a black caiman.

But the piranhas do not live just to eat. Not infrequently they themselves become food for the lake fishermen. In fact they comprise a stock of food always available under the stilt house, useful during bad weather or when the fisherman is panema, meaning the state of someone unable to fish (though depending 
on the intensity of the panemeira, even the piranhas may vanish). ${ }^{3}$ In normal situations, capturing them requires no more than dropping a hook and line or throwing a harpoon, a task preferentially assigned to children. Figuring among the preferred delicacies, either cooked or roasted over the fire, sliced opened lengthways still scaled, piranha is a catch generally consumed on the lakes themselves or back in the village, the broth made from the fish being widely proclaimed as a sexual stimulant.

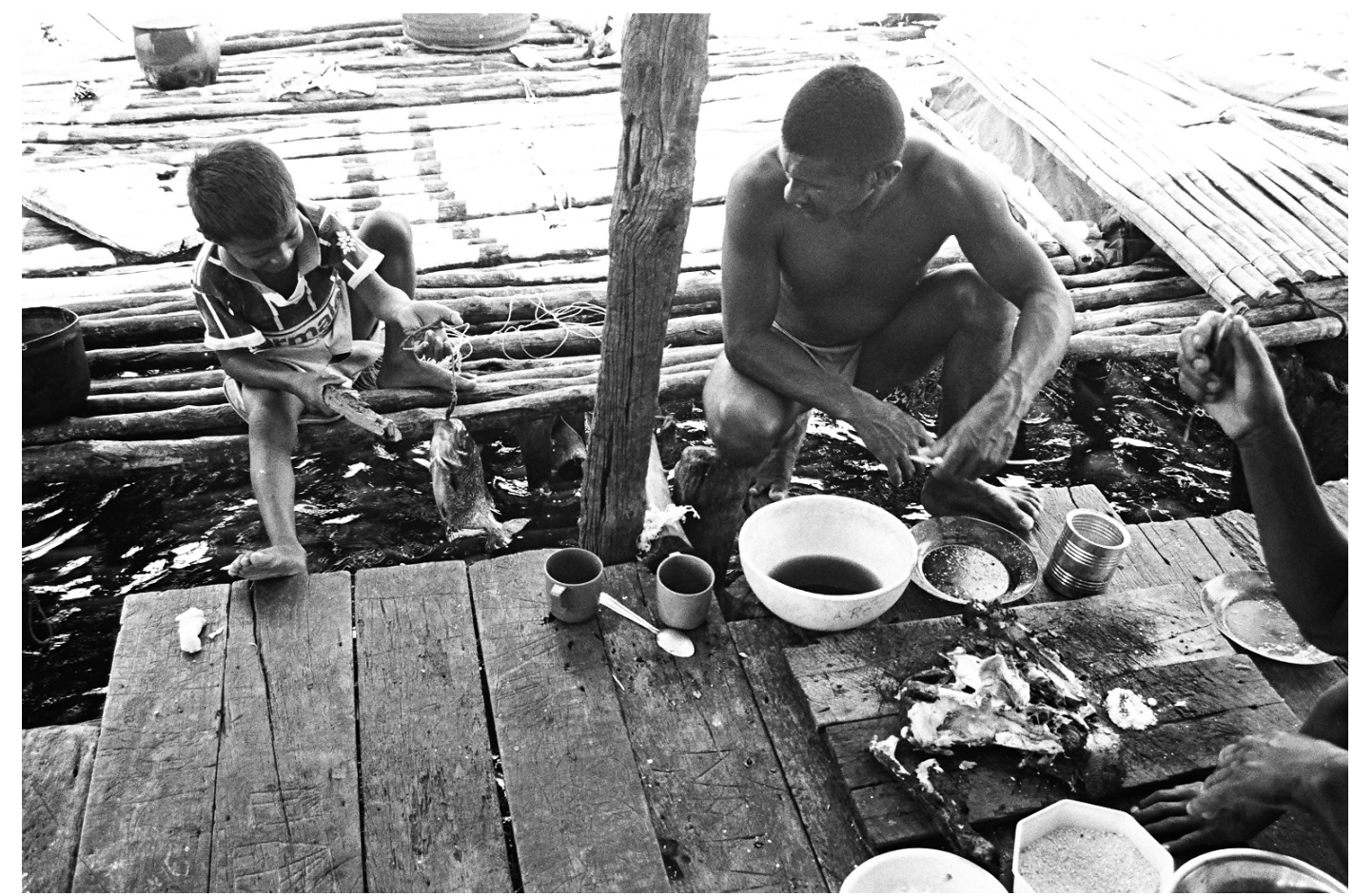

Figure 2 - Eating a meal while the boy on the left, Passarinho, takes advantage of the arrival of the piranhas to capture them with a hook and line. His father Antenor keeps him alert to the risks of handling such powerful jaws. (Author's photo)

This conviviality between piranhas and lake fishermen drew my attention during the research not only because of their constant presence in the everyday life of the stilt house, but also because - while studying the predation of different species in this lake region, especially the pirarucu (Arapaima gigas) the ambiguous case of the piranhas suggested a reflection on the meanings and limits of the notions of predation and domestication. Faced with the conviviality established between fishermen and fish, I found myself intrigued in a sense similar (though opposite) to what Ingold (1976) experienced in his field research in Lapland, when he arrived to study herders and was unable to find a single reindeer in the surrounding area, since they were 'herded' in an extensive model more like 'game.' Expecting predation everywhere, I became intrigued by the commensality and something like conviviality between two of the region's most inveterate carnivores.

In the case of these Amazonian lakes, the piranhas cannot be said to be either a target of fishing like the other fish, or domesticated in any strict sense of the term, nor indeed familiarized in the sense established by South American lowland ethnology. Here I refer to the debate led principally by Descola (1994 and 2013: 514 Ss.) and Erikson (1987 and 2012) and developed in more recent works like those of

3 A broad concept, panema is understood also as a state of incapacity to catch prey that can afflict hunters and fishermen and is found throughout Amazonia. It usually derives from the failure to comply with precepts relating to the predatory activity, especially in terms of the treatment of the animal prey. Linked to the concept of panema, for example, is the idea that animals are persons and are controlled by a spirit owner of animals, who may or may not offer them to the fisherman or hunter. Hence one should not treat prey maliciously, capture too many or treat the remains of a hunted animal badly. Panema also involves the relations among neighbours and kin, and affects objects and animals (e.g. Da Matta 1967, Galvão 1976, Almeida 2013). 
Vander Velden (2012), which have increased the analytic and ethnographic density of the theme. In Sucuriju village, the place where the lake fishermen that I discuss here reside, only the breeding of 'exotic' fauna is controlled, such as dogs, some pigs and chickens, painstakingly kept safe from the periodic inundation of the tides and the attacks of jaguars and feral or domestic dogs. On the other hand, there is the familiarization of Amazonia fauna, such as parrots, monkeys and even a giant otter (Pteronura brasiliensis) which accompanied the fishermen on their expeditions, swimming beside the canoes. Though not fitting any of these other situations exactly, a carnivorous conviviality nonetheless exists between piranhas and lake fishermen to some kind of mutual advantage - a conviviality that challenges any narrow use of the domestic/wild, breeding/predation oppositions, as well as their intermediary operator, familiarization, or indeed any moderating term like proto- or semi-domestication, since there is no indication that this relationship will develop into a more advanced stage of domestication.

So it is from this angle that I return, then, to my earlier sense of unease, focusing on the ambiguous character of the piranhas as a motive and a point of entry for discussing the equally ambiguous potentialities and limitations of the notion of domestication. Above all, I shall look to emphasize its value not only in facilitating exchanges of viewpoints between anthropology and other areas, but also between anthropologists and the persons and animals with whom they conduct research. Rather than affirming the notion of domestication, the aim is to explore its dilemmas as vectors of an ethnographic approach to the relation between humans and animals.

\section{Reconsidering domestication}

First of all we need to examine the recent revival of the term domestication in the context of studies of animals, particularly in social or cultural anthropology. From the outset we can recall that in the discussions on domestication, anthropology habitually deploys concepts that come from other disciplines, such as archaeology and evolutionary biology. Put otherwise, while social and cultural anthropology spent some decades omitting this concept from its main debates, adjacent fields continued to produce a variety of new approaches. In archaeology, for example, the notion of domestication has undergone significant transformations, pointing to something more processual, qualified as gradual, reversible, multiple, mutual, unintentional and unforeseen (Lien 2013: 13).

Sketching a panorama of some of the transpositions of this term to anthropology, Nerissa Russell (2002) demonstrates how, roughly speaking, two lines of understanding of domestication can be distinguished, one of them favouring a view of the human control of reproduction, emphasizing the intentionality of Anthropos, and another indicating two-way relations. O'Connor (1997), for example, analysing the cases of domestic rats and sparrows, argues that it is a mistake to conceive domestication as the exploitation of other animals by humans, arguing instead that it involves mutualistic relations that benefit them both. Clutton-Brock (1994) meanwhile stresses that humans benefit more and have modified animals contrary to their ideal forms of adaptation, emphasizing the ideas of control and captivity. Perceptively, Russell (2002: 289) observes that this controversy is conditioned by the definitions of 'benefit,' which do not necessarily need to be limited to reproductive success and that also leads to a debate on temporal scales and units of analysis (individual, population, species). For social anthropology it seems to me that this is a paramount question to be answered by ethnography.

The book organised by Cassidy and Mullin (2007) is precisely one such work in which various authors explore the impact of these debates within the field of anthropology, presenting questions and proposals based on empirical studies. In the articles gathered in the volume, various types of situations have persuaded anthropologists to rethink anthropocentric definitions of domestication: diseases, 
commensality and unplanned interactions, unconscious selection through alterations in the environment, architecture, cohabitation, the rearing of wild animals in safari parks or by environmentalists, fish farming, and undesired commensality as in the case of rats and sparrows.

Various scholars, including some archaeologists, have contributed to the critique of the emphasis given to notions like human ownership and control in favour of more flexible and symmetric forms of connection like cooperation and exchange. Some go further, arguing that it was plants and animals that domesticated humans. In light of this situation, what would be the consequences of exploring an idea like codomestication, for instance? In the introduction to the volume, Cassidy $(2007,20)$ astutely observes that the challenge is not only to rethink domestication in light of the new technologies and new kinds of encounters between humans and animals, but also to emphasize an older problem: namely that domestication is an extremely diverse process, always transforming and without predefinitions. As a consequence the contrast between positions closer to mutualism or closer to an idea of human domination can take on diverse formats in this debate (Cassidy 2007: 10).

Helen Leach argues for an emphasis on reciprocity, such that we can even speak of human domestication in a properly biological sense. Leach (2003) argues that a parallel can be discerned between the morphological transformations of animals and humans in the Pleistocene and the Holocene, though the explanations are normally linked to different arenas and criteria, one to the ambit of human evolution, the other to studies of animal domestication. She argues therefore that in acknowledging this correlation between transformations based on the close coexistence between species, the notion of domestication, in order to be maintained, can no longer be founded on the idea of human domination and intentionality (Leach 2003: 359).

It should be noted, however, that although playing an important role in the current 'reappraisal' of the notion of domestication in contemporary discussions of nature and culture, this type of parallelism is far from being a novelty in social or cultural anthropology (cf. Lien 2015: 11-2). Boas (1938) himself had already used the expression 'human domestication' in an effectively morphological acceptation. On the other hand, the inversion of the meaning, or the symmetry in the recognition of effects deriving from the conviviality between humans and animals was also observed by Mauss. The author criticized the anthropocentrism embedded in the idea of domestication, adding that while humans could be said to have domesticated dogs, we should also consider that it was cats that domesticated humans (Mauss 2006: 123). In a specific ethnographic context, Evans-Pritchard (2007) referred to the Nuer as symbionts, parasites or slaves of the cattle and also claimed that their idiom was bovine, associating the terms of their social life with the dynamic of their relationship with the animal - here citing merely the classics from three different traditions and three distinct perspectives on this human/animal symmetry.

While the problems caused by a narrow definition of domestication has bothered anthropology for some time, the more recent dissatisfactions express the eclosion of the critique of the nature/culture distinction, setting the tone for new conceptual and theoretical explorations. However, it is worth noting that while the current shift towards a 'reappraisal' tends to recognize a symmetry in relations, employing expressions like mutualism, symbiosis and reciprocity, this has not involved outright rejection of the term domestication. Neither is the aim to offer a new and more adequate definition. Russell (2002: 285) suggests that it would be extremely difficult to formulate a satisfactory definition for animal domestication since the broad spectrum of human/animal relations are not suited to the wild/domestic dichotomy or the distinction between biological and social. Even so, or precisely because of this fact, the objective is to maintain the notion on account of its analytic power (Russell 2002: 297) and heuristic value (Leach 2003: 359), as well as its potential for comparison and for mobilizing connections and continuities through different themes and temporal domains (Lien 2015:5). Hence this kind of reaffirmation of the notion of domestication is based precisely on making explicit and exploring the larger and insoluble antinomies implied by it. 
Indeed, by preserving and potentializing the dilemmas intrinsic to the notion of domestication, this option proves inspiring. The result is not so much a formula to discern, classify and give meaning to determined phenomena (which would involve insuperable problems of levels and criteria), but a way to instigate a series of debates and controversies pervaded by such tensions that can act as means to ethnographic understanding, including domination-mutualism, wild-domestic, nature-culture, intentionchance. On the other hand, maintaining this term - not only in a metaphoric and symbolic sense prevalent in the anthropology of the second half of the twentieth century (Shanklin 1985, Russell 2007 and Cassidy 2007) - lessens the chances of anthropological approaches moving away from their focus on the dynamic of practical interactions that should be central to examination of the theme.

Russell (2007: 41) proposes that rather than attempting to decide between alternative ways of defining or recognizing domestication, we can understand it better by elucidating its practices through studies dedicated to classifying the human and the non-human, forms of intimacy or familiarization, power and property, and the regulation of reproduction. I am sympathetic to this view, but I believe that this recent movement of interest in the relations between humans and animals, including the reconsideration of domestication, has generated more conceptual and epistemological contributions than actual empirical approaches (Lien 2013: 22-3), if it is still possible to express the issue in these terms.

In other words, while the intention to reposition symmetrically anthropological premises concerning the relations between humans and animals has been highly successful, I think that some major impasses still remain when it comes to the question of how to develop this shift ethnographically (here I obviously refer to the form taken by approaches, not to ready-made models). How to rethink the role of human discourse and actions vis-à-vis other kinds of data in the anthropological inquiry into human relations with animals? In this setting various fundamental debates have been pursued with important theoretical reconfigurations. I have the impression, though, that less emphasis has been given to rethinking the conditions under which the ethnography of relations between humans and animals is developed in response to this thought-provoking scenario of symmetries and the attempt to overcome the epistemic premise of the nature/culture distinction.

In the Brazilian case, a further remark is worth making. The recent wave of studies on relations between humans and animals, initially propelled by ground breaking research into science and sociotechnical innovations and by the recent trends in indigenous ethnology, as well as animals studies, still seems relatively timid in terms of its concern with the so-called rural world - farmers, peasants, fishermen, breeders, agricultural technicians and so on - despite more recent efforts in this direction being observable (e.g. Stoeckli 2015, Leal 2015, Froehlich 2016, Nascimento 2016). This would seem all the more relevant insofar as peasant studies in Brazil traditionally emphasized dimensions other than the human relation with the animal and plant worlds, which at the very least points to an ample field of research yet to be explored.

This conjunction between a re-discussion of the terms of the notion of domestication, associated with an ethnographic interest in the theme, makes it an opportune moment to revisit two distinct ethnographic approaches to the relation between humans and animals. Both are directly linked to the theme of domestication and can contribute to overcoming what I would venture to describe as a certain limitation to the empirical approach that we seem to encounter when the ethnography presents situations like the relation between fishermen and piranhas discussed here. As so often happens in anthropology, the best insights are behind us.

With this in mind, I turn to the explorations of animal domestication undertaken in the $1980 \mathrm{os}$ in the context of the French anthropology of technique and also in the early works of Tim Ingold on reindeer. My intent here is not to produce an exegesis or a replication of the proposal of these authors, but to 
emphasize the stances that allow them to connect specific ethnographic situations with the wider problem of domestication, which implies another temporal scale and a greater level of generality and an open interdisciplinary dialogue. Avoiding metaphorical associations or analogies, these two perspectives seem to offer alternatives to deal with themes that are still valid in the current disciplinary scenario with a radical critique of the nature/culture distinction and its conceptual derivatives. Both approaches are founded on closely exploring the complexity and variety of the relationship between humans and animals. Rather than narrowing down definitions, they are interested in thinking about the processes designated by the term domestication and its various levels and meanings, exploring, for example, its connections and combinations with the relation of predation.

\section{Domestication as action and system}

We began with Jean-Pierre Digard, one of the principal names of the French anthropology of technique, a research tradition derived from the work of Marcel Mauss (2006) that received less attention outside France. The author of an indispensable text on the topic, L'homme et les animaux domestiques, Digard (2009 [1990]) argues that domestication should be comprehended as a process, not a fixed state but a continuum of possible relations. He proposes the concept of 'domesticating action,' which helps avoid the idea of unilineal progression. It makes no sense, therefore, to ask about the 'first' or 'true' domestications, nor whether a particular animal is domesticated or not, but to focus rather on specific domestication practices.

It is not just a question here of a rhetorical manoeuvre, but a way of privileging an approach that avoids preconceptions about human relations with animals. The dialogue with branches of animal biology, including zootechnics, is not undertaken with the intention of importing arguments but to think about them as factors whose meaning emerges within a particular 'domesticating system.' Hence there are no impossibilities or facilities in a general sense but always in relation to each domesticating system, which includes a system of social relations and conceptions.

Despite manipulating the distinction between practice, the social and representations, Digard seeks to stress precisely an equivalence between social relations (among humans) and relations with animals in a domesticating system (Pelosse 1991). He adopts a dynamic perspective in two senses: the first synchronic, that is, comprehending domestication through the 'behavioural chain' in a truly interactive acceptation; the second diachronic, or historical, recuperating processes of domestication, feralization, etc. Hence liminal situations held in a limbo by the domestic-wild relation are taken not as extraordinary but as entirely commonplace in the overall flow of relations between humans and animals. "Everyday, in all parts of the world (more or less) cats, dogs, horses and pigs 'return' to living wild” (Digard 1988: 34). Rather than just passing through a transitional phase, "there are many animals that remain in this limitrophe situation: Andean camelids, reindeer, pigs in New Guinea, elephants in Asia, etc." (idid: 35). In a way, this historical view neutralizes the strangeness that can be caused by situations taken to be hybrid.

From this perspective, the 'limit cases' should be the main focus of inquiry, a zone where the presuppositions surrounding domestication and its principles are thrown into question and the wealth of variants and components involved in the domesticating process become more clearly visible (Digard 2009 [1990]: 35). Digard (2009 [1990]: 254) is thinking here of examples like the 'selective hunting' of the vicuña in the Andes, located between hunting and breeding, closer to a process of territorial management than the blind predation of a species. These limit cases have been foregrounded in studies of the relation between humans and animals in general and domestication in particular. Here it suffices to cite the well-known example of animal non-domestication developed by Descola (1994), the studies of Felipe Vander Velden (2012) 
on cattle, chickens and dogs among the Karitiana, or indeed the inspiration behind the present text, the relation between piranhas and fishermen.

Notably Digard asserts the validity of the term domestication, but as an omnibus category encompassing extremely diverse processes that involve distinct patterns of relations between humans and animals. Moreover the nuances in this area are extremely important: familiarized, tamed, trained, acclimatized, captive, confined, as well as the differences in scale - individual, group, species, etc. (Digard 1988: 33).

Influenced by André Leroi-Gourhan (1971 and 1973), Digard argues that ethnography focused on the "means of acting on the animal," such that external classifications, based on zoology, geography or economics immediately prove inadequate. Another point is that the type of relation involved can only be determined through the ethnography of interactions taking place in a given situation. In many cases of gregarious animals, for instance, the privileged unit of analysis should not be the species or the animal but the group: it is at herd level that actions should be comprehended (size, composition, behaviour, movement, feeding, etc.). It is these relational aspects, rather than the animal, species or the broader characterization of the activity (cattle breeding or fishing, for example), that should be foregrounded in the ethnographic study. Here we should be cautious when it comes to adopting presuppositions concerning the species or the relations between humans and animals, since the relevant relations may not be there.

Following a similar line of analysis, François Sigaut agrees that domestication is a technical fact and, as such, can only be understood through a finely detailed and painstaking ethnography of its practical interactions. Hence cattle breeding cannot be analysed in a generic sense, where the notion of species would serve as a guarantee, since it will differ depending on whether the cattle provide work, milk, beef or leather, for example. Sigaut (1980) had put forward this argument in a well-known article where, based on the elaboration of a series of products supplied by different animals, he criticizes the alimentary hypothesis that had informed most studies of domestication. Instead he advocates an approach to domestication from the animal's perspective (Pelosse 1991), without, though, avoiding the fact that it is used by humans.

Sigaut seeks to show that the meaning and use of the animal are not linked to a zoological unit (species) but to the 'products' that it generates. Products not only in an economic sense, but corporal products, energy, behaviour and signs. He thus opens up the animal's black box, so to speak, insisting that its meaning is always relative to a relational and partial context. Furthermore, this approach to products and techniques enables us to think through the various kinds of relations with the animal, avoiding the privileging of one kind in advance. We can also recall that, from this perspective, the 'products' are not determining factors but innovations that only exist within the set of practices associated with them. The animal's energy only becomes a product when the means and conceptions for using it are present in a given ethnographic situation. This implies that, just like zoological definitions, the categories used to identify human groups economically are misleading at an ethnographic level. Sigaut points to the risk of employing expressions like hunter-gathers or nomadic herders unreflectively in anthropology given that one people might hunt to obtain clothing while another plants crops for the same purpose.

Both Sigaut and Digard insist on the reciprocal character of the relation of domestication, despite the first being sceptical concerning the usefulness of the term as a concept given its amplitude. For Digard the act of domestication has effects on humans and animals, and all the means of action have multiple effects. Hence the staff used to ward off predatory animals serves to herd the domesticated animals. Fences prevent the flock from scattering but are also used to count, separate and organise. Likewise when humans provide and assist reproduction, they are provoking further transformations in behaviour (Digard 1988: 44).

The empirical sensibility to reciprocity, mutualism or the active participation of animals in the process of domestication is even more clearly expressed by another anthropologist, a student of Mauss, André-Georges Haudricourt. Examining both animal and plant domestication, Haudricourt (1969) claims 
that social relations themselves are homologous to the relations with nature. Even so he avoids making any standardising determinist correlation, such as considering that peoples who breed animals inevitably present certain social configurations. Through a comparison - somewhat anachronistic and overly generic, we could add - between the domestication of animals and plants and the forms of government in the Mediterranean and China, he asserts that what matters are the modes of relation. Herding (and all the ramifications involved in driving a herd) employs a kind of direct and positive action that stipulates the presence and direction of a herder. On the other hand, the perspective of Chinese gardening and animal breeding privileges indirect negative action where the aim is to eliminate obstacles and allow the fluidity of actions of the domesticated or controlled living being. Hence domestication actions or forms of pastoralism can involve radically distinct relational modes. This, indeed, is the conclusion reached by two commentaries on the recent appropriation of the notion of domestication. One by Rival (2012a), who evokes Haudricourt to critique Knight's opposition between hunting and domestication. The other by Ingold (2015: 27), when he rereads his own interpretation of the transition from trust to domination, emphasizing the existence of different 'models of domination.'

For Haudricourt the mode of acting is linked to a particular pattern of relations and traverses both the social environment and the sphere of actions on nature. He goes even further, showing that human actions are in fact interactions, in the strong and comprehensive sense of the term, since they need to be understood through a direct dialogue with the potential for action of plants and animals. This intuition is not developed by the author but seems to follow the same set of references made by Haudricourt and Dibie (1988) sometime later, connecting Gregory Bateson and Jackob von Uexkull (2010), in order to stress the importance of comprehending the animal's perspective and its communication.

As Carole Ferret (2012) shows in her development of Haudricourt's proposals, this amounts to an anthropology of actions between humans and non-humans. Since such action involves living beings, it is never just an acting, but a making others act. In other words, the technique involved in domestication is always relational in kinds because it also includes the action of the plant or animal. But this project depends on an ethnography sensitive to these interactions, which can be of diverse types. Digard's work provides precisely the sensibility and methodological apparatus needed for this kind of project.

\section{Domestication, ecology and perception}

The other significant contribution, which takes a number of similar directions, is the early work of Tim Ingold. I should explain that I am not arguing here for a pure and simple reapplication of the anthropological proposals of these French works and Ingold's first texts - the moments and dilemmas of anthropology are different today. What I wish to emphasize here is that these works are extremely successful in terms of articulating the conceptual and methodological discussions within a zoological and ecological context (especially apropos domestication) with ethnographic situations without submitting the latter to the former. I believe, indeed, that this work contains important elements for responding to discussions commonly evoked by the adoption of a symmetrical approach to relations between humans and animals, seeking to avoid materialism or natural determinisms and, simultaneously, anthropocentrism or sociocentrism, while at the same time dialoguing with studies from other areas.

This arises precisely from the fact that what they sought to foreground in this interdisciplinary dialogue were the means of exploring the diverse forms of action or relationship between humans and animals, rather than remaining at a discursive level or establishing concepts and classifications. This is why, despite the differences between the French authors cited above and Ingold, I emphasize their shared aim of expanding the term domestication such that it becomes divested of its analytic and descriptive 
function and evokes, instead, a series of questions that can be explored ethnographically. This leads to the insertion of new concerns, more relational and empirical than classificatory and generalizing - in the case of the French authors, as we saw, the premises of the anthropology of technique originating in Mauss; in the case of Ingold, a debate with ecology. Both succeed in developing a dialogue between ethnography and the questions involved in domestication in a properly dynamic and operative sense.

In his doctoral thesis on reindeer herding in the north of Finland, Ingold (1976) advances an idea that exerts a considerable influence in his ethnography and in his later writings: the reindeer is situated on a boundary that challenges the distinctions between the domestic and the wild, precisely because the elements qualifying these two notions are unequally distributed in the relational forms between humans and reindeer observed by himself in the field.

In one of the principal conclusions of his work, Ingold observes that a pattern of intensive-symbiotic pastoralism was eventually replaced by another pattern, extensive-predatory in kind, as the result of three factors: the deterioration of pastures, the adoption of motorized sledges, and the growth in the market for reindeer products (Ingold 1976: 29). This would explain his initial puzzlement on arriving in the field and failing to encounter any animals in the area surrounding the human groupings that he considered to be herders (Ingold 2001). This led him to re-discuss the notion of domestication through, for instance, the critique of the idea that the more established the capitalist dynamic, the more intense the control of a species - on the contrary, an emergence of extensive dynamics was revealed including techniques proximate to hunting.

But the main aspect of Ingold's approach, which has a clear impact on later and better known developments of his work, as I have argued in a previous work (Sautchuk \& Stoeckli 2012) and as Ingold (2013) himself indicates more recently, is his attention to reindeer behaviour in order to understand this herding configuration - such as the tendency to follow a leader, to be attracted by the sound of bells and to cluster together in the presence of a dog (Ingold 1976: 36 ). Ingold shows that the study of these societies depends on perceiving that these animals have their own very particular way of moving through a territory, as well as their own organisation. Reindeer, he argues, are animals that tend to be hierarchically organised and capable of recognising themselves as individuals with distinct functions within their group (1976: 20). All this leads him to consider the reindeer not as a natural object or input to be appropriated, but as a being possessing volition, in continual movement and engagement with the environment and with humans.

In his subsequent work, Hunters, pastoralists and ranchers, based on new field research and a survey of ethnographies on reindeer, Ingold (1980) is sharper in his conclusions, explaining that "the difference between hunting and pastoralism lies not in the particular characteristics of the animals themselves, but in the productive relations that link animals and men" (1980: 82). But the productive here for Ingold (just as for Sigaut) is not related to a strictly economic or utilitarian approach. To demonstrate this idea, then, he seeks out tools that can explore the direct relation between humans and reindeer in group situations and individually.

This leads to two propositions that I consider more relevant. The first resides in the complexification of the notion of domestication, which leads to a clear recognition of the distinction between the terms taming, herding and breeding, the confusion of which causes innumerable misunderstandings. For example, the control of the reproduction of animals, breeding, typically connotes the relation of taming and the animal's status for domestic work (Ingold 1980: 124). Ingold, though, asserts that this amounts to a confusion, since one process does not precondition the others. Adopting a similar approach to Sigaut's, Ingold conceptualises domestication through three not necessarily concomitant processes. Taming signifies familiarizing the animal, approximating it to human conviviality, not axiomatically treating it as property; herding signifies possessing animals as property, even if they are not tamed or their 
reproduction is not controlled. Finally breeding refers specifically to the control of reproduction, or to what is called 'morphological domestication,' even if the animals continue to live wild. Various intensities and combinations can also occur between these three processes.

We can take the case of groups of animals in rancher-type economies, which are domesticated from the reproductive viewpoint, but are not necessarily tamed, living free across very large areas. An inverse situation applies to tamed animals used by hunters as bait, though without implying that are they rounded up or that their reproduction is conditioned by human actions. The pastoralists studied by himself, for their part, neither tame nor control reproduction, they merely herd. In Ingold's words: "It will not do to refer to such combinations as states of 'semi-domestication,' for the implication that they are in the process of evolution towards 'full' domestication is not always warranted" (1980: 82). Put otherwise, like Digard, Ingold considers these 'limit situations' to be full of meaning, revealing an inapplicability of the notions of domestication and wildness to which we are habituated.

The other important point is his elaboration of the distinction between predation, symbiosis and parasitism in order to comprehend the mechanisms of interaction with reindeer, which introduces an operational and dynamic character and a distinction of scale into this debate that are fundamental to his ethnographic approach. For example, he shows that while predation and parasitism are negative for individuals, at the level of the population this negativity may be annulled or even inverted. As we know, predators may perform a fundamental role in the long-term maintenance of prey populations. On the other hand, the symbiosis involved in reindeer herding contains a disequilibrium that can lead to abrupt transformations in the system of relations, proving negative for the species involved. To understand the transformations occurring to the relation with the reindeer in a historical sense, Ingold mobilizes these technical and ecological aspects in the comparison between the predation of reindeer by wolves and humans, and next associates this with an examination of the rationality of the structures of production and distribution of the products obtained in this relation (Ingold 1980: 143).

It is important to emphasize how Ingold and the French anthropologists make a similar move of reconfiguring the terms of what the relevant aspects in an ethnography may comprise. With this aim in mind, they dialogue openly not only with the conceptual frameworks but also the empirical approaches of biology, zootechnics, ecology, etc. And not simply to apply or submit to them, but to debate and discuss them through ethnography - that is, as vectors for reflection and research. This is very different from merely importing concepts or models from other areas since it involves an effort to resituate the ethnographic objective (including some anthropocentrism) via different empirical approaches. The return to these works apropos the notion of domestication is opportune precisely because they indicate paths towards a critique of the nature-culture distinction (or human-animal, subject-object) which goes beyond a theoretical-reflexive endeavour.

For example, their approaches avoid reifying the biological category of species, or even the presupposition of two poles in what we call the relation between humans and animals. Moreover, the rejection of a notion, its substitution, is not by itself the solution to underlying epistemological problems. Some dilemmas can indeed be paralysing and deserve to be abandoned, but reject completely concepts could mean, very often, ignoring the accumulated discussions and complexities surrounding certain questions. 


\section{What is a human? Anthropos and domestication}

One question that may certainly surface is the relevance of continuing to employ the term domestication given the conceptual and epistemic reformulations shaping contemporary anthropology. Here it is worth localizing some of the research and analyses that point to different reasons for doing so. To start with we can cite the more general approaches to the emergence of animal domestication, as explored, for instance, in the ethnology of Siberia by Willerslev et al. (2014) or in Amazonia by Descola (1994 and 2013: $377 \mathrm{ff}$.). These approaches work to articulate contemporary ethnological themes (especially animism and sacrifice) with the emergence (or not) of animal domestication over the long durée, seeking to reach a certain degree of generality in their interpretations. Both adopt a narrower definition of domestication to undertake their analyses and manipulate relatively clear contrasts between hunting and herding (and also between domestication and pet keeping) on one hand, and between practice and ideology (or discourse) on the other. Curiously (or perhaps symptomatically) they arrive at opposite conclusions for Amazonia and Siberia. While for Descola (1994 and 2013: $377 \mathrm{ff}$.) the animist conceptions rendered animal domestication meaningless (by being incompatible with predation), for Willerslev et al. (2014) they led precisely to domestication, as a form of extending or perfecting the meaning of the hunt. It would perhaps be pointless to compare these two ethnohistorical interpretations of domestication, especially at a moment when Amazonia and Siberia have emerged as a promising axis of dialogue in anthropology (e.g. Brightman et al. 2012).

This adoption of a narrower meaning of domestication by Descola and Willerslev et al., which also applies to Ingold (2000: ch. 4; cf. Sautchuk \& Stoeckli 2012), contains a number of aspects worth noting. It involves a strategy of dialoguing with other areas, projecting contemporary anthropological perspectives particularly the accumulation of studies on the human relation with animals - into a more general debate (such as the relation between hunting and herding). Despite proposing other interpretations for the meaning of domestication, thereby destabilizing ethnocentric visions of the past - whether that of other peoples or of a supposed Humankind - the use of the notion of domestication in a narrow sense may elicit reservations from anthropologists immersed in the ethnographic complexity of the relations with animals. This can be seen in two recent approaches to the monkeys in Japanese reserves (Knight 2011) or the growing population of exogenous animals in the United States (Jaclin 2013) - both of them problematizing the relation between the wild and domestic and rethinking the meanings of these notions.

Perhaps this is a case of seeing this diversity as well as a difference of scale and intention in the employment of concepts, perceiving which debates and audiences these authors are addressing. Whatever the case, the fact is that while domestication has been reactivated as a central notion by some anthropologists, including in a new approach to the debate on so-called 'origins' (also see Rival $2012 \mathrm{~b}$ for an example relating to the plants) and in the contemporary production of wild animals, the discussion of what has been understood by the term remains preeminent. I believe that the definition of concepts in anthropology has to be recognised as particularly open to their manipulation, ambiguity and transformations in different contexts (Gellner 2003). It seems to be precisely this that emanates from the debates that have been promoted on the theme, demonstrating the effort to bring together perspectives or even researchers from other areas, such as archaeology and biology, as well as historical and ethnographic studies. ${ }^{4}$

4 The course taken by Ingold's work perhaps offers the best demonstration of the variations that the notion of domestication can acquire in anthropology. From a tool for exploring the interspecific relations between humans and reindeer (Ingold 1976 and 1980), domestication becomes reconfigured as a way of repositioning the relation between humans and animals at the level of evolution (1987), is then rethought in the context of a critique of industrial society (2000) and, finally, has its value as a concept dissipated by the idea of an omnipresence of life (Ingold 2011) (cf. Sautchuk \& Stoeckli 2012). However, this has not stopped Ingold (2013) from recently emphasizing the importance of his early ethnographic findings on the relation between the Skolts and the reindeer to the later development of his reflections on humans and animals. In fact, domestication was always associated in Ingold's work with a question that forms the correlate of the title of the famous book edited by himself - What is an Animal? (Ingold 1988). Returning to examine the phenomena associated with domestication leads, in other words, precisely to reposing the terms of anthropology itself. Inquiring into domestication does not mean just including animals in the anthropological approach, it also means asking, in a sense: what is a human? 
If we look back on the last three decades, we can observe a degree of persistence in the efforts to reflect collectively on domestication in anthropology. The publication of the special issue of the journal L'Homme in 1988 (v. 28, n. 108, 'Les Animaux: domestication et représentation') was followed by an event held in Japan in 1992 (Ellen \& Fukui 1996, see especially Harris 1996), another held in the USA in 2004 (Cassidy \& Mullin 2007) and, in 2016, the conference Domestication and hybrid communities: coexistence, coevolution, cooperation, held in France. At all these moments it is possible to note a double character of seeking to reaffirm the term at the same time as looking to stretch and even unravel its semantic field, making room for the complexity of ethnographic situations. This seemed particularly evident in the French event, and the group of biologists, anthropologists and archaeologists agreed to think of domestication in relation to notions such as interaction, mutualism, symbiosis, reinserting into the discussion, for example, the ideas of domination and intentionality.

A good example of the results of this kind of stance in more in-depth ethnographic studies is the work of Lien (2015) who, based on her research into salmon farming in Norway and Tasmania, has creatively explored the notion of domestication. Firstly she employs the term to facilitate a broad interface with other areas without adopting their perspectives, but also without bypassing them. Her objective is to explore the kind of analytic work that domestication enables, especially as an idea that can be connected with other ideas (Lien 2013: 7). Precisely because it is a fluid, highly mutable concept, "domestication works (...) as a comparative tool that mobilizes connections and continuities across various temporal and topical domains" (2015:5). The idea is that certain dilemmas contained in the notion of domestication may be useful precisely for anthropology to comprehend differences.

But for Lien the key point of this revival of the concept is the need to renew the empirical approach with practical situations of domestication:

What we need is perhaps not so much yet another philosophical exercise to define the Anthropos, but a multitude of ever more attentive ethnographies that trace domestication practices on and off the beaten tracks that the archaeological road atlas has left us. What I propose is not a post-human anthropology, not even a posthuman ethnography (we enter the field as human beings, always), but an ethnography that admits a broader and fuzzier version of Anthropos, one that inhabits the entangled and multiple and indeterminate relations of growing, feeding, killing, caring, eating, swallowing and digesting in its multiple versions. (Lien 2013: 22-3)

She associates the idea of domestication with the need for a turnaround in the form of examining these themes in the field, leading the ethnographer to reinsert Anthropos into debate. This to me seems an interesting solution and the proposals presented above seem to offer a basis for advancing in this kind of enterprise. It is interesting to note too how Lien associates the notion of domestication with the idea of becoming proposed more recently by Ingold (2011). Even though Ingold's critique of the notions of species and organism make the idea of domestication lose emphasis in his thought, Lien shows that it is possible to examine domestication through new agendas.

Observing the tone in which the academic debate on domestication has been conducted, as well as the revival of its use in anthropological studies, the impression that emerges is that the potentialization of the unease and tension provoked by the notion of domestication has been productive for the research into the multiple possible relations between humans and animals. There seem to be a reason: it simultaneously establishes a line of communication and enables the exchange with researchers from other areas, not only about their results but also about their approaches. In a period when neologisms have proliferated, the critical and open potential evinced by the way in which the term has been adopted perhaps explains the relative resilience or even recuperation of the notion in anthropology. 


\section{When piranha becomes ox}

We can return then to the piranhas under the lake fishing stilt houses, briefly exploring the paths that the questions raised by these reflections on domestication suggest can be taken in this specific case. The presence of these aquatic predators in the environment of the fishermen, their commensality, offers us the possibility of playing with the limits of the notion of domestication, articulating it with the primacy of predation existing here.

Were we to begin then with the kinds of relations developed between the lake fishermen and these fish, we would have to move beyond the alimentary interactions that contain a certain mutual benefit (if we take into account the dimension of scale). The intensive dissemination of piranhas through these lakes, which some fishermen locate between three and five decades ago, brought about various transformations in terms of fishing for small fish. Firstly, they imposed an important limitation on fishing with nets since the piranhas ruin the netted fish and the equipment if the fisherman does not remain continually on watch. Their voracity and speed also require the fishermen to be more skilled in the use of fishing line, making movements with the bait that can simultaneously attract desired fish and repel the piranhas. This is a game of cunning involving three parties: the fisherman mimicking a fruit or a small aquatic animal with his bait, the targeted species and their particular alimentary behaviours, and the piranhas, insatiable, rapid, but with almost no commercial value. Depending, however, on the fluctuations in their price on the regional fish market, the form of this interaction can change to the disadvantage of the piranhas...

On the other hand, the piranhas contribute to the reproduction of their own predators (the fishermen) and not just by becoming food. First they mark the pirarucu fish that have been in the basin of the lakes for some time since they bite their fins and tails. This establishes a distinction between the already experienced pirarucus - i.e. warier and more accustomed to the fishermen - and those that are still naive and curious, coming from the mangroves and marshes where there are no piranhas or laguistas. This provides the lake fisherman with value feedback to assess whether his strategy of approach and capture was correct or simply the result of a prey still unaware of the dangers existing in the lake basin. By feeding on living pirarucus, the piranhas produce a sign that over time enhances the lethal qualities of the laguistas in this kind of capture of sophisticated skills.

The piranhas, however, are also the main target of children's games. Always available below the stilt house, the children are encouraged to practice the diverse arts of fishing with these aquatic neighbours. In addition, the fish are eviscerated, descaled, prepared and salted by them, constituting a kind of child product, which the fishing patrons remunerate with enough money to buy sweets, thereby emulating the commercial fishing relationship itself.

It is very true that as soon as one of them is caught, the piranhas become wary and vanish from close to the stilt house for some time. This in itself, though, is still a positive aspect since in paying close attention to the movements on the surface, the fish observe and respond to the gestures of the apprentice harpooners, quite unlike most other fish. This interactive capacity of this fish in fact represents the most complex challenge to be faced by the future harpooner of pirarucus. If we consider its agile movements and small size, therefore, the piranha comprises a valuable simulator, always available to children and youngsters during their long apprenticeship in the sophisticated art of harpooning pirarucu (Sautchuk 2015).

Even so it is clear that the piranhas are far from matching the idea of a domesticated animal, in the narrow sense, since their reproduction is not controlled, nor are they tamed. It could be said that they are lured to gather under the stilt houses by the food, meaning that they are in some sense rounded up and fed by the lake fishermen. The laguistas themselves, however, consider this situation atypical since a predator has no need to be offered food. So even though the idea of breeding piranhas is never conjectured, except jokingly, the relation of conviviality with the fish is very different from the kind experienced with caimans. 
The latter are the visceral enemies of the laguistas, even though a mutual respectful distance is maintained between them. The piranhas are fed, certainly, but never with the sense that that such action contributes to the development of a being under the feeder's control. It is more about fomenting voracious behaviour and the remarkable aggressive capacities of the fish. The laguistas stimulate this conviviality because it fits into the dynamics of their own sociality in the stilt houses. Any conviviality as such consists precisely of incorporating this aggressive potential rather than dampening or annulling it. On the surface, we could compare this phenomenon to feeding 'wild' animals in safari parks (e.g. Knight 2005), but here we are not dealing with the production of a wild other but precisely with the incorporation of a similarity. In other words, while the tourist who offers food produces wildlife as an alterity, the laguista feeds the piranha as a factor of similarity. While in the former case domesticating practices produce the wild animal, in the latter the fish's predatory disposition is absorbed into the domestic ambient of the stilt houses.

One point that makes this clear is that the piranhas are never conceived as property that the residents of a stilt house can dispose of freely, since these fish are covered by the same type of 'hunting ethics' as other animals. To clarify this point: one time I spent the whole afternoon harpooning piranhas swimming under the stilt house, exercising my modest abilities with the harpoon, in order to catch some food for dinner and also implement my strategy of learning as a form of doing ethnography (Sautchuk \& Sautchuk 2014). During the night, feeling pain in my shoulder, I climbed out of my mosquito net to look for some painkillers in my bag. In the morning, Macó, the harpooner who was leading me, asked what I had been doing and immediately decided to leave that particular stilt house to set up residence in another location. It transpired that the owner spirit of the lake, who controls its animals, including the piranhas, had disliked my uncontrolled attitude, killing haphazardly, and demonstrated the fact through the nocturnal pain. The warning having been given, it was essential to comply. If the piranha is a xerimbabo, a pet, its owners are not the lake fishermen.

In fact, a wide range of interactions is present here and some kind of coexistence based on predation is even established between these two predators of the lakes. Although the fishermen cannot (and generally have no wish) to simply decimate the piranhas, including for the reason that they are not theirs to dispose of, neither are the fish considered a threat as such. True, this carnivorous presence under the stilt house causes the lake fishermen to adopt some precautions, but only to the extent of not jumping into the water when pitiú (imbued with the smell of recently handled fish) or at the moment when the piranhas are eating. Some avoid placing extremities like hands or feet in the water in isolation, which may be attacked like pieces of meat. Even when they take to the water, during the aquatic games, I never heard of any accident, aside from one case or other of someone being nibbled, taken as a mistake or exaggeration, understandable in a usually respectful but still reciprocally carnivorous conviviality. 


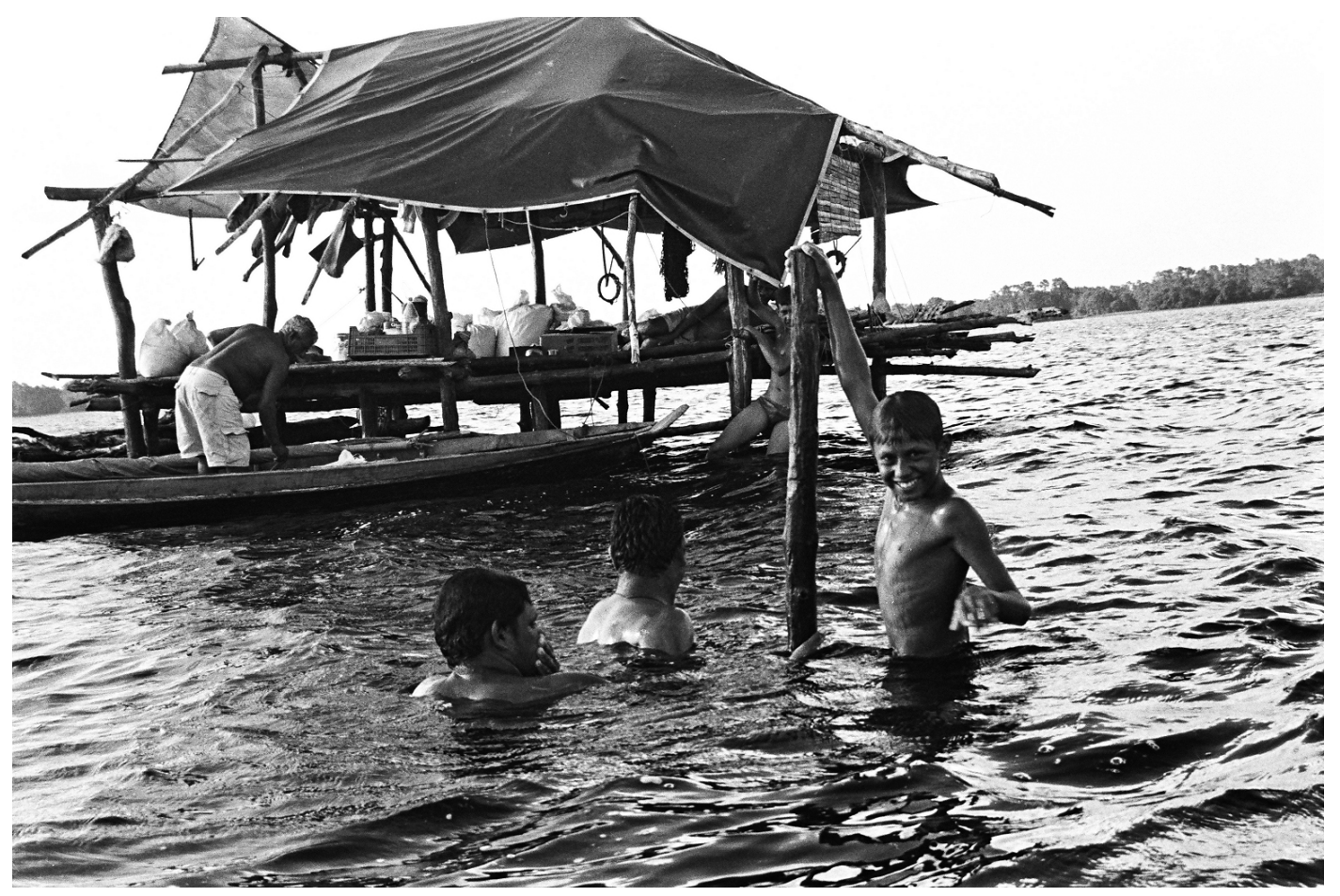

Figure 3 - Bathing or playing tag in the water take place without any mishaps, save when eating fish or handling them. (Author's photo)

This brief ethnographic exercise allows us to say that, first of all, it would be mistaken to frame this situation in terms of relations between species or between humans and animals. We need to think in terms of a broader system that includes the type of relation with other fish, objects and even owners of animals. Another important point is that dispositions and relations vary according to situations and depend on other factors. While children take advantage of the piranha's capacity to escape and react in order to develop their own skills in handling the harpoon, the adults improve their own sophisticated perceptual and predatory skills through the piranha's capacity to attack the pirarucu at speed, marking it. As a consequence, the very idea of what is a positive or negative relation depends on the positions and the type of interaction. If we consider just the perspective of the laguistas, the piranha participates in the training of the children in the condition of prey, while with the adults it contributes by attacking the same fish - which means a different kind of relationship.

In conclusion, if we wish to investigate the idea of some kind of proximity and mutual benefit between fishermen and piranhas, we need to consider the diverse relational modes in which they are mutually implicated. This includes the stilt house itself and the overlapping of dwellings that it generates, as well as the harpoon and its form of acting in opposition to (children) or in conjunction with (adults) the action of the piranhas. In the case of these aquatic beings, the commensality with laguistas is certainly positive in a collective sense, but may have lethal consequences for individuals. In Brazil, the expression boi de piranha, 'piranha ox,' is applied to the animal given to this fish when the herd crosses a river, allowing the rest to traverse unscathed - it is, therefore, a symbol of individual sacrifice for the benefit of the collective. The fact that a piranha may be in a position similar to that of the ox tells us a lot about the type of conviviality established there.

If the proximity with piranhas produces various effects for the fishermen, this is because the fish participate in the configuration of this predatory sociality in the midst of the stilt houses and the sophistication of its lethal capacities. The fact that they eat and are eaten in connection with the stilt houses situates them in a sui generis position in the configuration of this space. It is possible to speak of some 
form of conviviality - and even some aspects seen in the systems of domestication - but always thinking of them under the encompassing sign of predation, which marks them both, fishermen and piranhas. Hence the gesture of giving food to the piranhas and appreciating their disposition to act as commensals should not be seen as an attempt to control their behaviour or their life cycles nor to valorise a wild other. Ultimately, it amounts to a form of cultivating and modulating mutual aggressiveness - a practice of reinforcing predatory dispositions through proximity and carnivorous exchanges.

Translated by David Rodgers

Received, 31 January, 2016, Approved, 17 July, 2016.

\section{References}

ADAMS, Cristina; MURRIETA, Rui; NEVES, Walter e HARRIS, Mark (eds.). 2009. Amazon peasant societies in a changing environment: political ecology, invisibility and modernity in the rainforest. New York: Springer.

ALMEIDA, Mauro. 2013. "Caipora e outros conflitos ontológicos". R@U 5(1): 7-28.

BOAS, Franz. 1938. The mind of primitive man. New York: Macmillan.

BRIGHTMAN, Marc; GROTTI, Vanessa; ULTURGASHEVA, Olga (eds.). 2012. Animism in rainforest and tundra: personhood, animals, plants and things in contemporary Amazonia and Siberia. New York and Oxford: Berghahn Books.

CASSIDY, Rebecca. 2007. "Introduction: reconsidering domestication”. In CASSIDY, R.; MULLIN, M. (eds.) Where the wild things are now: domestication reconsidered. Oxford: Berg. pp. 1-25.

CASSIDY, Rebecca; MULLIN, Molly (eds.) 2007. Where the wild things are now: domestication reconsidered. Oxford: Berg.

CLUTTON-BROCK, Juliet. 1994. "The unnatural world: behavioral aspects of humans and animals in the process of domestication". In: A. Manning and J.A. Serpell (eds.), Animals and human society. London: Routledge. pp. 23-35.

DA MATTA, Roberto. 1967. "La panema : un essai d'analyse structurale." L'Homme, 7(3): 5-24.

DESCOLA, Phillipe. 1994. "Pourquoi les Indiens d’Amazonie n’ont-ils pas domestiqué le pécari ? Généalogie des objets et anthropologie de l'objectivation. In: B. Latour, P. Lemonnier (eds.), De la préhistoire aux missiles balistiques. Paris: La Découverte. pp. 329-344.

DESCOLA, Phillipe. 2013. Beyond nature and culture. Chicago: University of Chicago Press.

DIGARD, Jean-Pierre. 1988. "Jalons pour une anthropologie de la domestication animale". L'Homme, 28(108): 27-58.

2009 [1990]. L'homme et les animaux domestiques: anthropologie d'une passion. Paris: Fayard.

ELLEN, Roy. and FUKUI, K. (eds.). 1996. Redefining nature: ecology, culture and domestication. Oxford: Berg. ERIKSON, Philippe. 1987. "De l'apprivoisement à l'approvisionnement: chasse, aliance et familiarisation en Amazonie amérindienne". Techniques et Culture, 9: 105-139.

. 2012. "Animais demais... os xerimbabos no espaço doméstico matis (Amazonas)." Anuário

Antropológico, II/2011: 15-32.

EVANS-PRITCHARD, Edward E. 2007 [1937]. Os Nuer. São Paulo: Perspectiva.

FERRET, Carole. 2012. "Towards an anthropology of action: from pastoral techniques to modes of action". Journal of Material Culture, 19(3): 279-302. 
FROEHLICH, Graciela. 2016. O bem-estar na carne. Um estudo antropológico sobre as relações entre humanos e animais a partir da categoria de 'bem-estar animal'. Tese de doutorado em Antropologia Social, Universidade de Brasília.

GALVÃO, Eduardo. 1976. Santos e Visagens: um estudo da vida religiosa de Itá, baixo Amazonas. São Paulo: Editora Nacional.

GELLNER, Ernst. 2003. "Concepts and society”. In Ernest Gellner: selected philosophical themes, vol. 1. New York: Routledge. pp. 18-46.

HARRIS, David. 1996. "Domesticatory relationships of people, plants and animals". In: Roy Ellen and Katsuyoshi Fukui (ed.), Redefining nature: ecology, culture and domestication. Oxford: Berg. pp. 437-463.

HARRIS, Marc. 1998. "'What it means to be caboclo' : Some critical notes on the construction of Amazonian caboclo society as an anthropological object". Critique of Anthropology, 18: 83-95.

HAUDRICOURT, Andrés-Georges and DIBIE, Pascal. 1988. "Que savons-nous des animaux domestiques?" L'Homme, 28(108): 72-83.

HAUDRICOURT, Andres-Georges. 1969. "Domestication of animals, cultivation of plants and human relations". Social Science Information, 8: 163-172.

INGOLD, Tim. 1976. The skolt lapps today. Cambridge: Cambridge University Press. . 1980. Hunters, pastorialists and ranchers: reindeer economies and their transformations. Cambridge: Cambridge University Press. . 1987. The appropriation of nature: essays on human ecology and social relations. Manchester: Manchester University Press. .1988. What is an animal? London: Routledge. . 2000. The perception of the environment: essays on livelihood, dwelling and skill. London: Routledge. . 2011. Being alive: essays on movement, knowledge and description. London: Routledge. . 2013. "Anthropology beyond humanity". Suomen Antropologi:Journal of the Finnish Anthropological Society, $38(3): 5-23$.

. 2015. "Comment: from the master's point of view: hunting is sacrifice". Journal of the Royal Anthropological Institute, (N.S.)21: 24-27.

JACLIN, David. 2013. "In the (bleary) eye of the tiger: an anthropological journey into jungle backyards". Social Science Information, 52(2): 257-271.

KIRKSEY, Eben; HELMREICH, Stefan 2010. “The emergence of multispecies ethnography”. Cultural Anthropology, 25(4): 545-576.

KNIGHT, John. 2005. "Feeding Mr Monkey: cross-species food 'exchange' in Japanese monkey parks". In: John Knight, Animals in person: cultural perspectives on human-animal intimacies". Oxford: Berg, pp. 231253.

. 2011. Herding monkeys to paradise: how macaque troops are managed for tourism in Japan. Leiden, The Netherlands: Brill Academic.

LEAL, Natacha. 2015. Nome aos bois. Zebus e zebuzeiros em uma pecuária brasileira de elite. Tese de doutorado Programa de Pós-graduação em Antropologia Social, Universidade de São Paulo.

LEACH, Helen. 2003. "Human domestication reconsidered". Current Anthropology, 44(3): 349-368. LEROI-GOURHAN, André. 1971. Evolution et techniques I: l'homme et la matière. Paris: Albin Michel. . 1973. Evolution et techniques II: milieu et techniques. Paris: Albin Michel.

LIEN, Marianne. 2013. "Domestication as partial relations. Lively attachments and the anthropos of anthropology". Paper presented at the Sawyer Seminar workshop, University of California. $31 \mathrm{p}$. Mimeo. . 2015. Becoming salmon: aquaculture and the domestication of a fish. Oakland: University of California Press. 
_-_-_.; LAW, John. 2011. “'Emergent aliens': on salmon, nature, and their enactment”. Ethnos, 76(1): 65-87. MAUSS, Marcel. 2006. Techniques, technology and civilization. New York, Oxford: Berghahn Books [edited by N. Schlanger].

NASCIMENTO, Joelma. 2016. Refletindo sobre a domesticação: afetos e relações de poder entre sujeitos humanos e não humanos no interior da Paraiba. Master dissertation, Programa de Pós-Graduação em Antropologia da Universidade Federal da Paraíba.

O'CONNOR, Terence P. 1997. “Working at relationships: another look at animal domestication”. Antiquity, 71: 149-156.

PELOSSE, Valentin. 1991. “Comment penser la domestication animale?” L'Homme, 31(118): 133-139.

RIVAL, Laura. 2012a. "Comment on J. Kinight 'The Anonymity of the hunt: a critique of hunting as sharing"'. Current Anthropology, 53(3): 348-9.

RIVAL, Laura. 2012b. "Animism and the meaning of life: towards an understanding of manioc domestication”. In: M. Brightman, V. E. Grotti \& O. Ulturgasheva (eds.), Animism in rainforest and tundra: personhood, animals, plants and things in contemporary Amazonia and Siberia. Oxford: Berghahn. pp. 119-41.

RIVAL, Laura; DOYLE, McKey. 2008. "Domestication and diversity in manioc (Manihot esculenta Crantz ssp. esculenta, Euphorbiaceae)". Current Anthropology, 49(6): 1119-1128.

RUSSELL, Nerissa. 2002. "The wild side of animal domestication". Society \& Animals, 10(3): 285-302.

RUSSELL, Nerissa. 2007. “The domestication of anthropology”. In: R. Cassidy and M. Mullin (eds.), 2007. Where the wild things are now: domestication reconsidered. Oxford: Berg, pp. 27-48.

SAUTCHUK, Carlos. 2007. O arpão e o anzol: técnica e pessoa no Amazonas (Vila Sucuriju, Amapá). Tese de doutorado, Programa de Pós-Graduação em Antropologia Social, Universidade de Brasilia.

. 2015. "Aprendizagem como gênese: prática, skill e individuação". Horizontes Antropológicos, 21: 109-139. .; SAUTCHUK, J. M. M. 2014. "Enfrentando poetas, perseguindo peixes: sobre etnografias e engajamentos”. Mana, 20(3): 575-602. .; STOECKLI, P. 2012. "O que é um humano? Variações da noção de domesticação em Tim Ingold”. Anuário Antropológico, 2011/2: 227-246.

SHANKLIN, Eugenia. 1985. "Sustenance and symbol: anthropological studies of domesticated animals". Annual Review of Anthropology, 14: 375-403.

SIGAUT, François. 1980. "Un tableau des produits animaux et deux hypothèses qui en découlent". Production Pastorale et Société, 7: 20-36.

. 1988. "Critique de la notion de domestication". L’Homme, 28(108): 59-71.

STOECKLI, Pedro. 2015. Laços brutos: vaqueiros e búfalos no baixo Araguari - Amapá. Tese de doutorado em Programa de Pós-graduação em Antropologia Social, Universidade de Brasília.

UEXULL, Jacob von. 2010 (1934). A foray into the worlds of animals and humans (with a theory of meaning). Minneapolis, London: University of Minnesota Press.

VANDER VELDEN, Felipe. 2012. Inquietas companhias: sobre os animais de criação entre os Karitiana. São Paulo: Alameda Casa Editorial.

WILLERSLEV, Rane; VITEBSKY, P.; ALEKSEYEV, A. 2014. "Sacrifice as the ideal hunt: a cosmological explanation for the origin of reindeer domestication". Journal of the Royal Anthropological Institute, (N.S.)21: 1-23.

Carlos Emanuel Sautchuk

Department of Anthropology, University of Brasilia , Brasília/DF, Brazil. 